GESTA LEAL, Rogério. Riscos e possibilidades do ativismo judicial na democracia. Revista Eletrônica Direito e Política, Programa de Pós-Graduação Stricto Sensu em Ciência Jurídica da UNIVALI, Itajaí, v.16, n.1, $1^{\circ}$ quadrimestre de 2021. Disponível em: www.univali.br/direitoepolitica - ISSN 19807791

\title{
RISCOS E POSSIBILIDADES DO ATIVISMO JUDICIAL NA DEMOCRACIA
}

\author{
RISKS AND POSSIBILITIES OF JUDICIAL ACTIVISM IN DEMOCRACY
}

Rogério Gesta Leal ${ }^{1}$

\section{RESUMO}

O objetivo deste trabalho é verificar em que medida é possível conciliar ativismo judicial e democracia, considerando principalmente os desafios que se apresentam as relações sociais contemporâneas. A justificativa desta proposta se sustenta no fato de que o Poder Judiciário tem sido cada vez mais procurado para dar conta de demandas envolvendo as insuficiências das politicas públicas governamentais em face de direitos fundamentais. Demarcamos como problema da abordagem verificar se é possível superar eventuais tensões entre o excesso de ativismo judicial e a democracia enquanto representação politica também institucional de outros poderes, e como hipótese a premissa de que deva-se adotar, para a solução do problema, perspectiva ampliada da atuação do Poder Judiciário a partir da compreensão igualmente oxigenada da Democracia e dos seus outros legítimos protagonistas, sob pena do esvaziamento de instancias importantes de deliberação e decisão política quotidiano. A metodologia utilizada neste trabalho foi a hipotética dedutiva.

PALAVRAS-ChAVE: Ativismo Judicial; Democracia; Representação Política

\section{ABSTRACT}

The objective of this work is to verify to what extent it is possible to conciliate judicial activism and democracy, considering mainly the challenges presented by contemporary social relations. The justification of this proposal is based on the fact that the Judiciary has been increasingly sought to deal with demands involving the inadequacies of governmental public policies in the face of fundamental rights. We point out as a problem of the approach to verify if it is possible to overcome possible tensions between the excess of judicial activism and democracy as a political representation also institutional of other powers, and as a hypothesis the premise that it should be adopted, for the solution of the problem, the oxygenated

\footnotetext{
1 Desembargador do Tribunal de Justiça do Estado do Rio Grande do Sul, Doutor em Direito. Prof. Titular da UNISC. Professor da FMP. Professor Visitante da Università Túlio Ascarelli - Roma Trè, Universidad de La Coruña - Espanha, e Universidad de Buenos Aires. Professor da Escola Nacional de Formação e Aperfeiçoamento da Magistratura - ENFAM. Membro da Rede de Direitos Fundamentais-REDIR, do Conselho Nacional de Justiça-CNJ, Brasília. Coordenador Científico do Núcleo de Pesquisa Judiciária, da Escola Nacional de Formação e Aperfeiçoamento da Magistratura ENFAM, Brasília. Membro do Conselho Científico do Observatório da Justiça Brasileira. Coordenador da Rede de Observatórios do Direito à Verdade, Memória e Justiça nas Universidades brasileiras Secretaria de Direitos Humanos da Presidência da República.
} 
GESTA LEAL, Rogério. Riscos e possibilidades do ativismo judicial na democracia. Revista Eletrônica Direito e Política, Programa de Pós-Graduação Stricto Sensu em Ciência Jurídica da UNIVALI, Itajaí, v.16, n.1, $1^{\circ}$ quadrimestre de 2021. Disponível em: www.univali.br/direitoepolitica - ISSN 19807791

understanding of Democracy and its other legitimate protagonists, under penalty of emptying important instances of deliberation and daily political decision. The methodology used in this work was the hypothetical deductive.

KEY-WORDS: Judicial Activism; Democracy; Political Representation

\section{INTRODUÇÃO}

O tema do ativismo judicial hoje constitui-se em fenômeno político, institucional, acadêmico e até social, haja vista o espectro amplo de relevância e divulgação que tem obtido em todo o Ocidente (para dizer o mínimo).

O Poder Judiciário tem sido provocado por múltiplos protagonistas do Mercado, do Estado e da Sociedade para se manifestar sobre assuntos que vão desde a violação de Direitos Humanos e Fundamentais até os atinentes às deficiências de serviços públicos e abusos praticados por agentes econômicos.

Neste contexto em particular, estamos nos referindo ao ativismo judicial como o poder que tem a jurisdição ordinária e constitucional (e estes campos estão cada vez mais fundidos) de, por um lado, tomar decisões que afetam competências e atribuições do Legislativo e do Executivo; e, por outro, definir pautas e agendas de prioridades, demandas e políticas públicas através de processos e procedimentos que tem alargado imensamente as compreensões sobre o que significam normas (princípios e regras) constitucionais e infraconstitucionais, tanto em face da ampliação da legitimidade/legalidade democráticas dos intérpretes da Constituição (no plano político, argumentativo, filosófico e pragmático), como por decorrência do aumento da complexidade que as relações sociais e institucionais apresentam.

Tudo isto vai gerando profundas crises de identidade e efetividade entre os poderes do Estado, assim como déficits de fidúcia da Sociedade e do Mercado em relação a eles.

A despeito das consequências que tal postura do Poder Judiciário por vezes operam, o certo é que há pouca convergência de opiniões envolvendo o conceito 
GESTA LEAL, Rogério. Riscos e possibilidades do ativismo judicial na democracia. Revista Eletrônica Direito e Política, Programa de Pós-Graduação Stricto Sensu em Ciência Jurídica da UNIVALI, Itajaí, v.16, n.1, $1^{\circ}$ quadrimestre de 2021. Disponível em: www.univali.br/direitoepolitica - ISSN 19807791

e os limites do ativismo judicial, até porque as variáveis que compõem tais perspectivas são muito amplas.

Nossa intenção neste trabalho, portanto, é propormos a adoção de perspectiva ampliada da atuação do Poder Judiciário a partir da compreensão igualmente oxigenada da Democracia contemporânea e dos seus outros legítimos protagonistas, sob pena do esvaziamento de instancias importantes de deliberação e decisão política quotidiano.

Como metodologia de abordagem vamos utilizar a hipotético-dedutiva, partindo de algumas premissas teóricas no âmbito do tema eleito, para então avançar com proposições contributivas ao enfrentamento dos desafios que ele apresenta.

\section{QUAL ATIVISMO JUDICIAL: INTERPRETAÇÃO E APLICAÇÃO DA NORMA JURÍDICA}

Todo o conceito de ativismo judicial envolve, no mínimo, idiossincrasias mais individuais do que institucionais, influenciadas por concepções de mundo e vida distintos, bem como por ideologias e crenças as mais diversas sobre tais concepções. $^{2}$

Mesmo assim, podemos demarcar alguns elementos constitutivos deste fenômeno multifacetário capazes de oportunizar diálogos e práticas de entendimento racional. ${ }^{3}$

\footnotetext{
2 OLDFATHER, Chad M. Defining judicial inactivism: models of adjudication and the duty to decide. Disponível em: <http://ssrn.com/abstract=877002>. Acesso em 20 out. 2017.

3 Não vamos tratar aqui da origem espacial e temporal da expressão ativismo judicial, até porque neste ponto há divergências tópicas entre autores, e que não importam para o escopo desta reflexão. Ver o texto de KMIEC, Keenan D. Origin and Current Meanings of Judicial Activism. In California Law Review, Vol.92/1441

(2004), http://scholarship.law.berkeley.edu/californialawreview/vol92/iss5/4, acessado em 19/11/2017, advertindo para o fato de que o surgimento do ativismo judicial não teria ocorrido em 1804, quando o Chief Justice Marshall tratou do caso Marbury x Madison, por caracterizar-se esta decisão como judicial review e não judicial activism; e que o verdadeiro marco inicial deste ativismo teria ocorrido em 1610, quando o Justice Coke, na Inglaterra, ao julgar o caso Dr. Bonham, utilizou-se de doutrinas do direito natural.
} 
GESTA LEAL, Rogério. Riscos e possibilidades do ativismo judicial na democracia. Revista Eletrônica Direito e Política, Programa de Pós-Graduação Stricto Sensu em Ciência Jurídica da UNIVALI, Itajaí, v.16, n.1, $1^{\circ}$ quadrimestre de 2021. Disponível em: www.univali.br/direitoepolitica - ISSN 19807791

Em primeira linha de argumentação é fácil perceber que o ativismo judicial representa criativo processo de pensamento e decisão vinculante a todos os que se encontram submetidos a determinada jurisdição. Tanto o pensamento como a decisão precisam, todavia, estarem fundados em argumentos lógicos e razoáveis hauridos do sistema jurídico como um todo, passíveis de constatação e controles públicos, notadamente a partir de suas motivações; além do que tais decisões espelham - de forma mais ou menos intensa - certa coerência e integridade para com os precedentes jurisprudenciais que também constituem o sistema jurídico. ${ }^{4}$

$\mathrm{Na}$ perspectiva de Paul Mahoney, o ativismo judicial existe onde os juízes modificam o sentido da lei quando originariamente criada, substituindo a deliberação matriz do processo legislativo que Ihe deu vida.

Assim, o autor considera inválidas as ações ou decisões de juízes dadas com o propósito de buscar a justiça no caso concreto, ou interpretar a lei no sentido de conformá-la a novas realidades sociais emergentes, não permitindo a correção pelos fóruns adequados para tanto (Legislativo e Executivo, por exemplo). ${ }^{5}$

Outro importante autor indiano, Subhash Kashyap, sustenta que:

What has come to be called hyper activism of the judiciary draws its strength, relevance and legitimacy from the inactivity, incompetence, disregard of law and constitution, criminal negligence, corruption, greed for power and money, utter indiscipline and lack of character and integrity among the leaders, ministers and administrators. As a result of this a vacuum was created in which the governmental machinery seemed to be totally helpless with the corruption in legislative and executive fields. The vacuum was filled in by the judiciary. ${ }^{6}$

Em outra perspectiva, tem sido debatido no cenário internacional que o ativismo judicial tem se transformado em importante instrumento quando a máquina legislativa chega a impasses em determinados casos - para além, pois, de sua

\footnotetext{
4 Ver nosso texto LEAL, Rogerio Gesta. A decisão Judicial: elementos teórico-constitutivos à efetivação pragmática dos Direitos Fundamentais. Chapecó: UNOESC, 2012.

5 MAHONEY, Paul. Judicial Activism and Judicial. Self-Restraint in the European Court of Human Rights: Two sides of the same coin. In Human Rights Law Journal, Vol. 11, nr. 1-2 (1990), p. 57-88.

${ }^{6}$ KASHYAP, Subhash. The citzen and judicial reforms under Indian polity. London: Hammick's Legal Bookshop, 2003.

Do mesmo autor ver o livro Political reforms for good governance - a policy brief. Florida: W. Gaunt \& Co., 2007.
} 
GESTA LEAL, Rogério. Riscos e possibilidades do ativismo judicial na democracia. Revista Eletrônica Direito e Política, Programa de Pós-Graduação Stricto Sensu em Ciência Jurídica da UNIVALI, Itajaí, v.16, n.1, $1^{\circ}$ quadrimestre de 2021. Disponível em: www.univali.br/direitoepolitica - ISSN 19807791

inércia violadora por insuficiência normatizadora, oportunidade em que a jurisdição passa a protagonizar respostas tópicas que se generalizam em face dos efeitos de determinados julgamentos (as ações declaratórias de inconstitucionalidade e constitucionalidade, assim como as ações de descumprimento de preceito fundamental, no Brasil).

No caso específico das ações de descumprimento de preceito fundamental, o ativismo judicial se flexibiliza pela autorização legislativa de origem que the permite agir desta forma, assim como no mandado de injunção em que a ausência de disposição jurídica inviabiliza o exercício de direitos. Mas estas são situações autorizadas pelo Estado Legislador a partir de critérios e requisitos previamente atendidos.

De qualquer sorte, ainda em nível de argumentos de fundamentação da Democracia enquanto regime de governo, devemos lembrar que as bases de sua constituição sempre estiveram ligadas - direta ou indiretamente - a soberania popular e suas manifestações representativas, as quais deram origem constitutiva a organização física e institucional do Estado (legislativo, executivo e judiciário).

Nesta estrutura mais objetiva, a cada qual das funções estatais foram dadas competências e atribuições diversas e complementares, relacionadas entre si no que diz respeito ao gerenciamento dos interesses públicos da Comunidade, e equacionadas pela via dos check and balances.

Por certo que estes temas todos não estão enquadrados de forma matemática e inflexível, haja vista que há situações (algumas normatizadas), que autorizam iniciativas diferidas de protagonismo dos organismos estatais, o que é controlado em termos de excessos e insuficiências sobre a necessidade e proporcionalidade destas medidas. Por vezes, como fizemos referência acima, o Poder Judiciário é chamado pelo sistema jurídico para resolver problemas individuais, sociais e institucionais, todavia, cumpre questionar: (i) a natureza deste poder, e se ele é compatível com o conceito de Democracia que temos e queremos; (ii) se é suficiente para justificar e fundamentar o Poder da Jurisdição e seu exercício o fato dela ser prevista por Constituições Democráticas; (iii) ou se temos de insistir com a tese de que estes poderes jurisdicionais só existem para cumprir deveres/fins 
GESTA LEAL, Rogério. Riscos e possibilidades do ativismo judicial na democracia. Revista Eletrônica Direito e Política, Programa de Pós-Graduação Stricto Sensu em Ciência Jurídica da UNIVALI, Itajaí, v.16, n.1, $1^{\circ}$ quadrimestre de 2021. Disponível em: www.univali.br/direitoepolitica - ISSN 19807791

dentro dos marcos da Democracia que opera com o reconhecimento da legitimidade democrática de outros protagonistas oriundos da vontade popular que Ihes institui diretamente.

Analisemos melhor estas questões!

Em primeiro lugar, argui-se que inexiste propriamente poder judicial nas estruturas ocidentais de organização do Estado, mas funções judicantes em nível de check and balances. Todavia, a expressão poder judicial tem reiteradamente dois principais sentidos em linguagem jurídica: (a) um sentido funcional, isto é, da totalidade de atos os quais permitem que conflitos sejam julgados, (b) um sentido orgânico, que implica reconhecer que a totalidade das cortes de justiça representam certas exigências estruturais da própria Democracia.

A tese da ausência do poder judicial, por sua vez, geralmente vem sempre tomada em dois sentidos, no mínimo: (i) o de que inexiste um poder no sentido orgânico do termo quando nos referimos ao Judiciário; (ii) e o de que os juízes exercem funções que não lhes conferem especificamente forma real de poder. ${ }^{7}$

Quando estes dois argumentos falham, torna-se cada vez mais lugar comum recorrer a uma terceira tese: a de que pode existir um poder judicial, eis que a Democracia não é o que um povo vaidoso deseja, e tampouco pode ser genericamente identificada com o poder/vontade de maiorias, razão pela qual a verdadeira Democracia reside igualmente, e por vezes, no poder do Estado Juiz contramajoritário. ${ }^{8}$

Diante destes cenários revela-se importante estabelecermos, sempre, pactos semânticos - e sintáticos - necessários à delimitação do que entendemos por poder judiciário e como ele se projeta em cada realidade ou contexto social e político espacial e temporalmente. Em França, por exemplo, muitas discussões da teoria constitucional e mesmo da teoria política contemporânea lembram que o título VIII

\footnotetext{
7 Ver o texto de TROPER, Michael. The Judicial Power and Democracy. In http://dianan.iue.it:8080/bitstream/handle/1814/7714/EJLS $2007 \quad 1213$ TRO EN.pdf? sequence=18isAllowe $\underline{\mathrm{d}=\mathrm{y}}$, acesso em 25/06/2018. Ver também o texto de SUNSTEIN, Cass R. A Constitution of many minds. Princeton: Princeton University Press, 2009.

${ }^{8}$ Ver 0 texto de VERMEULE, Adrian. Judging under uncertainty. Cambridge: Harvard University Press, 2006.
} 
GESTA LEAL, Rogério. Riscos e possibilidades do ativismo judicial na democracia. Revista Eletrônica Direito e Política, Programa de Pós-Graduação Stricto Sensu em Ciência Jurídica da UNIVALI, Itajaí, v.16, n.1, $1^{\circ}$ quadrimestre de 2021. Disponível em: www.univali.br/direitoepolitica - ISSN 19807791

da Constituição vigente refere-se ao judiciário como autorité judiciaire, mais do que du povoir judiciaire.

A despeito disto, se estes termos favorecem em alguma medida a extensão de competências para as Cortes judiciárias, ou mesmo influenciam em sua independência, eles não chegam a formatar possibilidades de ampliação de poderes significativos aos órgãos judicantes. ${ }^{9}$

Se estas questões mais sintáticas não nos ajudam a compreender os fenômenos que levam a eventuais protagonismos excessivos e desequilibradores dos poderes de Estado, temos de levar em conta - para além do Judiciário - as funções institucionais dos poderes da mesma forma constitucionais do Legislativo e Executivo, que possuem competências e atribuições especializadas fundamentalmente em termos de iniciativas. Então é necessário que cada uma destas autoridades desempenhe suas funções institucionais em tempos e espaços específicos, tomando em conta que estes são muito distintos no que diz com a velocidade de processos/procedimentos e respostas, já que demandam distintas formas de legitimidade democrática.

Explicamos, (i) as autoridades legislativas precisam observar ritos e prazos especiais que regulamentam os processos de criação de normas que vincularão a todos (iniciativa de leis, comissões de avaliação, procedimentos de discussão e votação), tudo a ser gestado em tempo e espaços adequados; (ii) as autoridades executivas precisam destas normas autorizadoras para gerar políticas e ações públicas concretizadoras das escolhas/determinações legislativas referidas, as quais igualmente reclamam formas e procedimentos próprios (orçamentos aprovados, editais de licitação, procedimentos de concorrência regulares, contratações públicas a efetivar, execução de obras e serviços); (iii) as autoridades judiciárias precisam observar, sempre, o devido processo legal das demandas que Ihes acorrem - dentro de suas competências próprias -, garantir a ampla defesa,

\footnotetext{
9 Ver o interessante texto da La Ligue Des Droits de L'Homme, intitulado Le pouvoir judiciaire et la separation des pouvoirs sous pression. In http://www.liguedh.be/wpcontent/uploads/2017/05/avril2017 analyse Idh pouvoir quilibre pouvoirs.pdf, acesso em 25/06/2018. Na mesma direção ver o texto de BRUN, Henri \& LEMIEUX, Denis. Politisation du pouvoir judiciaire et judiciarisation du pouvoir politique: la séparation traditionnelle des pouvoirs a-t-elle vécu? In Les Cahiers de droit, 18(2-3), 265-313, 1977. doi:10.7202/042167ar
} 
GESTA LEAL, Rogério. Riscos e possibilidades do ativismo judicial na democracia. Revista Eletrônica Direito e Política, Programa de Pós-Graduação Stricto Sensu em Ciência Jurídica da UNIVALI, Itajaí, v.16, n.1, $1^{\circ}$ quadrimestre de 2021. Disponível em: www.univali.br/direitoepolitica - ISSN 19807791

o contraditório, o duplo grau de jurisdição, os direitos adquiridos, o que demanda também certos prazos a serem observados.

Eventuais dissonâncias de tempos e espaços no exercício das competências e funções destas autoridades podem gerar - como tem acontecido - tensões entre demandas individuais e sociais e suas respectivas respostas. A equalização destes conflitos - alguns aparentes e outros reais - exige cuidados institucionais muito sensíveis, sob pena de criarmos sinergias negativas entre as autoridades estatais e que afetam as legitimidades democráticas da representação politica contemporânea.

Por outro lado, não podemos simplesmente imaginar que as soluções oriundas do ativismo judicial são pacíficas, porque há vários tribunais que tratam da mesma matéria em face dos graus distintos de jurisdição, o que não raro geram distintas compreensões dos conflitos/fenômenos que Ihes chegam à decisão; ou seja, no âmbito do próprio Poder Judiciário vamos encontrar formas de decidir diferentes sobre os mesmos temas, partes e casos, e isto ocorre por várias razões, desde aspectos envolvendo a formação política e jurídica dos magistrados, passando por questões eventualmente ideológicas, culturais e mesmo em face de origens e condicionamentos religiosos, étnicos, raciais e de gênero.

Diante destes argumentos, queremos sustentar que não podemos falar em ativismo judicial do Poder Judiciário como um todo, porque isto implicaria comportamentos institucionais uniformes e coesos da fração de poder de Estado que ele representa, e não de alguns de seus órgãos fracionários ou monocráticos.

E tal não ocorre, nem mesmo quando contamos com certas estruturas de poder e de hierarquia institucionais estabelecidas para evitar dissensos exagerados em termos de atos jurisdicionais vinculantes (como é o caso, no Brasil, das sumulas vinculantes, dos recursos repetitivos, da repercussão geral, dentre outros ${ }^{10}$ ), isto

\footnotetext{
${ }^{10}$ A Repercussão Geral foi criada pela Emenda Constitucional n. 45/2004 e regulamentada em 2007. A ferramenta é de uso exclusivo do STF, e impossibilita a análise de recursos extraordinários que não atendam critérios de relevância jurídica, política, social ou econômica, indo além do interesse das partes envolvidas. Além de reduzir a quantidade de recursos no STF - somente entre 2007 e 2010 houve uma queda de $71 \%$, segundo dados da corte - esse filtro também afeta a tramitação nas outras instâncias. Isso ocorre porque os processos sobre o mesmo assunto ficam paralisados nos tribunais aguardando o julgamento da Suprema Corte, que tem efeito multiplicador. Por sua vez, os
} 
GESTA LEAL, Rogério. Riscos e possibilidades do ativismo judicial na democracia. Revista Eletrônica Direito e Política, Programa de Pós-Graduação Stricto Sensu em Ciência Jurídica da UNIVALI, Itajaí, v.16, n.1, $1^{\circ}$ quadrimestre de 2021. Disponível em: www.univali.br/direitoepolitica - ISSN 19807791

porque a Constituição Federal brasileira garante ao magistrado liberdade para julgar, mas a pergunta que temos de nos fazer é quais os níveis de discricionariedade permitidos a este magistrado em seu ofício que o Estado Democrático de Direito aceita - se é que existem ${ }^{11}$

Não há dúvidas sobre o fato de que o exercício da jurisdição implica o uso de discricionariedade enquanto condição de eleger, de maneira fundamentada, dentre várias possibilidades de escolhas que se apresentam no ordenamento jurídico, a que traduz maior conveniência e oportunidade para o interesse público em jogo, mas isto é controlado, seja pela via da retratação, fruto da interlocução processual; seja pela via do duplo grau de jurisdição.

Por certo, entretanto, que há situações particulares - e estas se repetem no tempo e espaço cada vez mais - marcadas por fatores e contextos não programáveis, porque decorrentes de variáveis incontroláveis e inéditas, não previstas pelos atores públicos ordinários que administram interesses públicos e privados. ${ }^{12}$ Para além disto, os atos cotidianos de gestão destes interesses, em regra, não são atribuídos a uma autoridade específica ou outra, individualmente, mas a grupos de autoridades que tomam decisões colegiadas (isto ocorre tanto no setor privado como público), até em face da complexidade das demandas e problemas cotidianos a serem solvidos e suas interconexões necessárias com multiníveis de campos e áreas envolvidas direta e indiretamente com aqueles.

Recursos Repetitivos foram instituídos no Superior Tribunal de Justiça (STJ) com a Lei n. 11.672/2008. O objetivo é dar mais celeridade, isonomia e segurança jurídica no julgamento de recursos especiais que tratem da mesma controvérsia jurídica. Esses casos podem ser selecionados por amostragem - cabe ao presidente ou vice-presidente do tribunal de origem admitir um ou mais recursos que melhor representem a questão repetitiva e encaminhá-los ao STJ para julgamento. In http://www.cnj.jus.br , acesso em 02/07/2018.

11 Para Michel Troper: In order to maintain that the role of tribunals is in conformity with democracy, one either should deny that they dispose of a discretionary power, and claim that they limit themselves to the application of a pre-existing law without the ability of expressing ideological preferences or making axiological choices, or one should conceive an organisation in which they are not endowed with such a discretionary power. TROPER, Michel. The judicial power in Democracy. In

http://dianan.iue.it:8080/bitstream/handle/1814/7714/EJLS $2007 \quad 1213$ TRO EN.pdf?sequence=1\&isAllowe $\mathrm{d}=\mathrm{y}$, p.06, Acesso em 02 jul. 2018.

12 Vamos pensar nas situações de surtos de dengue, malaria, enchentes, vendavais, incendios, ou outros acidentes naturais. 
GESTA LEAL, Rogério. Riscos e possibilidades do ativismo judicial na democracia. Revista Eletrônica Direito e Política, Programa de Pós-Graduação Stricto Sensu em Ciência Jurídica da UNIVALI, Itajaí, v.16, n.1, $1^{\circ}$ quadrimestre de 2021. Disponível em: www.univali.br/direitoepolitica - ISSN 19807791

Então, diante de demandas complexas e inéditas que envolvem deliberações de pessoas físicas e jurídicas, publicas e privadas, poderemos ter situações que desbordem do autorizado pela ordinariedade normativa vigente, dando vezo a respostas produzidas na flagrância destas, passiveis de serem questionadas sob o prisma da legalidade estrita. Tais comportamentos, por vezes, não são individuais (e mesmo que fossem), mas resultados de manifestações colegiadas, e também aqui o tema da responsabilidade deverá contar com aferição adequada.

A despeito destas particularidades, o modelo kelseniano de sistema jurídico ocidental (hegemônico no Brasil) - ao menos o da Teoria Geral do Direito da década de $1960^{13}$ - , não distingue entre criação da lei e aplicação da lei, colocando os juízes como criadores de normas e a decisão judicial em si mesma como norma, no sentido de que as leis sempre permitem aos juízes importantes protagonismos em termos de margens de decisão sobre suas aplicações em face de casos concretos, por exemplo, quando permitem aos magistrados eleger, no âmbito penal e fundamentadamente, qual a quantidade de pena adequada ao caso, se pode ou não ser substituída a pena de prisão por outra alternativa; sobre a extensão dos efeitos secundários da condenação penal (indenizações civis, suspensão de direitos políticos); em termos de condenações civis também, envolvendo indenizações por diversos tipos de violações normativas e fáticas. Em tais situações, por vezes, a moldura da norma fornece tão somente diretrizes a serem observadas na efetivação do direito.

Esta perspectiva do sistema jurídico e sua atuação está fundada na premissa de que os juízes não criam normas gerais, isto porque é preciso a autorização do próprio sistema para que a jurisprudência crie tais normas pela via dos processos judiciais, o que mantém hígido o principio democrático da divisão de poderes e deveres.

Outra versão deste debate - dentre tantas - é a que sustenta que os juízes não podem dispor de poderes discricionários - como a de Ronald Dworkin, em especial

\footnotetext{
13 Ver KELSEN, Hans. Teoría Pura del Derecho. Edición de 1960. Buenos Aires: Eudeba, 2009. Tradução de João Baptista Machado. Numa perspectiva mais reducionista desta postura de protagonismo judicial em face do sistema jurídico vigente, ver o texto do mesmo autor KELSEN, Hans. Teoría Pura del Derecho. Edición de 1934. Madrid: Trotta, 2011.
} 
GESTA LEAL, Rogério. Riscos e possibilidades do ativismo judicial na democracia. Revista Eletrônica Direito e Política, Programa de Pós-Graduação Stricto Sensu em Ciência Jurídica da UNIVALI, Itajaí, v.16, n.1, $1^{\circ}$ quadrimestre de 2021. Disponível em: www.univali.br/direitoepolitica - ISSN 19807791

diante do argumento das respostas corretas, pois, de acordo com autor norteamericano, os juízes não podem aplicar a lei a partir tão somente de raciocínios silogísticos, mas ainda assim têm que fundar soluções para os casos concretos que julgam com base no sistema jurídico vigente como um todo, deixando de exercer poderes de criar leis (law-creation powers). ${ }^{14}$

Por certo que métodos ou técnicas de interpretação e aplicação silogística da norma não se sustentam em seus fundamentos, haja vista que nenhuma norma nunca é constituída - em tese - para atender casos concretos, mas para dar conta de situações que ela prevê abstratamente. É preciso então determinar, antes de qualquer coisa, a qual (ou quais) situação normativa o caso a ser julgado pertence (norma-principio, norma-regra, de natureza civil, criminal, administrativa, etc.). Em outras palavras, é fundamental que o magistrado, em sua ação pragmática de julgamento, inicie por determinar estes elementos, que não são dados a priori, mas sempre se afiguram como resultados de operações cognitivas, compreensivas e, então, decisionais. Assim, a norma não é somente a norma geral, mas sempre a sua expressão de sentido aplicada a casos; e não é possível determinar se os casos pertencem a certas situações sem ter minimamente ideia do significado mesmo das expressões/sentidos que, por sua vez, as definem.

O sistema jurídico, de qualquer sorte, seja na perspectiva kelseniana, seja na de Dworkin, jamais impõem limites ao julgador para que tome decisão específica como critério geral, mas sempre permite a ele certa margem de apreciação, razão pela qual não podemos aceitar o argumento de que a decisão judicial deve ser considerada democrática pelo simples fato de ser derivada de leis e sistema jurídico democraticamente constituídos, pois mesmo em regimes de governo democráticos, com ordenamentos jurídicos democráticos, é possível termos decisões administrativas, políticas e jurídicas antidemocráticas.

\footnotetext{
${ }^{14}$ Ver os textos de DWORKIN, Ronald. Taking Rights Seriously. Boston: Harvard University Press, 1977; (ii) A Matter of Principle. Boston: Harvard University Press,1985; (iii) Law's Empire. Boston: Harvard University Press, 1986; (iv) Life's Dominion. New York: Vintage Books, 1993; (v) Freedom's Law. Boston: Harvard University Press, 1996; (vi) Sovereign Virtue: The Theory and Practice of Equality. Boston: Harvard University Press, 2000; (vii) Justice in Robes. Boston: Harvard University Press, 2006; (viii) Is Democracy Possible Here? Principles for a New Political Debate. Princeton: Princeton University Press, 2006; (ix) Justice for Hedgehogs. Boston: Harvard University Press, 2011.
} 
GESTA LEAL, Rogério. Riscos e possibilidades do ativismo judicial na democracia. Revista Eletrônica Direito e Política, Programa de Pós-Graduação Stricto Sensu em Ciência Jurídica da UNIVALI, Itajaí, v.16, n.1, $1^{\circ}$ quadrimestre de 2021. Disponível em: www.univali.br/direitoepolitica - ISSN 19807791

E tem mais, se o juiz reformula a lei no ato de sua aplicação, é a norma reformulada mesma que passa a deixar de ser democrática, pois, violados seus sentidos matriciais em face do que fora estabelecido pelo Parlamento, restando a cidadania submetida, ao fim e ao cabo, a regras de convívio e comportamento que, para além dos ditames e parâmetros publicamente constituídos pela legitimidade do processo legislativo, restam instabilizadas por eventuais margens de discricionariedade decisional dos magistrados diante de casos concretos. Tais decisões casuísticas tem se projetado, em alguns casos, para muito além das partes envolvidas na demanda solvida, atingindo cenários coletivos e difusos que deveriam contar com a maturada reflexão e decisão da representação política adequada, como é o caso do controle concentrado de constitucionalidade e seus efeitos.

\section{POSSIBILIDADES DE CONTENÇÃO DA DISCRICIONARIEDADE JUDICIAL COMO PROBLEMA DA DEMOCRACIA CONTEMPORÂNEA}

Por certo que a opção do positivismo jurídico para tentar conter na medida do possível os níveis de discricionariedade e hiperativismo judicial sempre foi o elaborar, de forma clara e precisa, normas/códigos que reduzissem a necessidade da atribuição de sentido aos seus comandos. ${ }^{15}$

A sistematização ordenada e integrada de regras e princípios jurídicos garante certo controle decisional demarcando suas possibilidades minimamente gramaticais - o que nunca foi (nem será) suficiente para aprisionar os limites de escolhas dos julgadores, por razões múltiplas de natureza epistêmica e hermenêutica.

Ou seja, a pretensão do sistema jurídico em constituir bases de organização/comportamento social que cubram campos amplíssimos das relações intersubjetivas e interinstitucionais, para além de tentar reduzir suas

${ }^{15}$ Ver os textos de: (i) LEAL, Rogerio Gesta. Hermenêutica e Direito. Santa Cruz do Sul: EDUNISC, 2002; (ii) ROCHA, Leonel Severo. Epistemologia Jurídica e Democracia. Canoas: Editora Unisinos, 1998; (iii) STRECK, Lênio Luis. Hermenêutica Jurídica em Crise. Porto Alegre: Livraria do Advogado, 2013; (iv) MENGONI, Luigi. Ermeneutica e Dogmatica Giuridica. Milano: Giuffre, 2006. 
GESTA LEAL, Rogério. Riscos e possibilidades do ativismo judicial na democracia. Revista Eletrônica Direito e Política, Programa de Pós-Graduação Stricto Sensu em Ciência Jurídica da UNIVALI, Itajaí, v.16, n.1, $1^{\circ}$ quadrimestre de 2021. Disponível em: www.univali.br/direitoepolitica - ISSN 19807791

complexidades, também tem o escopo de mitigar o exercício desmesurado das subjetividades no ato de decidir (no plano jurisdicional, administrativo e parlamentar), porém, isto se cumpre parcialmente, pois já restou evidenciado ser impossível evitar a existência de lacunas ou mesmo contradições nos sistemas jurídicos vigentes.

Isto ocorre, dentre outras razões e por um lado, por decorrência de que o legislador não pode prever todos os casos de variações relacionais entre fato e norma (principalmente em sociedades de riscos e perigos cada vez mais inéditos e iminentes); de outra banda, códigos normativos, não raro, até em face da complexidade das matérias que tratam, são elaborados com categorias e narrativas vagas e ambíguas, que rendem plurívocas possibilidades interpretativas. ${ }^{16}$

Para além disto, as modulações normativas dos sistemas jurídicos, sejam provocadas por eventuais caducidades de suas disposições, sejam decorrentes de embates de interesses sociais, devem ser alvo de monitoramento/alteração legislativa, notadamente em nome da independência, competência e autonomia dos poderes. ${ }^{17}$

Quando a atualização/regeneração (de forma mais conservadora ou inovadora) destes sistemas normativos deixam de ocorrer, seus déficits de legitimidade e eficiência sofrem impactos profundos, gerando tensões e conflitos que, eventualmente orquestrados pelas mídias, mas mesmo assim não sensibilizando - Parlamento, chegam ao Judiciário com apelos retumbantes distinguidos (econômicos, sociais, culturais, étnicos, raciais, de gênero).

\footnotetext{
${ }^{16}$ Ver os excelentes textos de: (i) ZANNONI, Eduardo A. Crisis de la razón jurídica. Buenos Aires: Astrea, 2005; (ii) CRUET, Jean. A vida do direito e a inutilidade das leis. Lisboa: José Bastos \& Cia., 1990; (iii) WARAT, Luis Alberto. Senso Comum Teórico: as vozes incógnitas das verdades jurídicas. In: Introdução Geral ao Direito. Porto Alegre: Fabris, 1994.

17 Podemos ter em mente os debates sobre a descriminalização do aborto no Brasil, em que o Congresso Nacional, recentemente, defende que esta matéria seja decida por ele, e não pelo Supremo Tribunal Federal - STF, haja vista a Arguição de Descumprimento de Preceito Fundamental - ADPF 442, na qual o PSOL pede que o STF declare inconstitucionais os artigos do Código Penal que criminalizam a mulher que realiza ou autoriza um aborto, assim como os profissionais que o fazem. Ver o site http://www2.camara.leg.br/camaranoticias/noticias/direito-e-justica/558279-deputadosdefendem-que-congresso,-e-nao-stf,-decida-sobre-descriminalizacao-do-aborto-no-brasil.html, acesso em 13/08/2018.
} 
GESTA LEAL, Rogério. Riscos e possibilidades do ativismo judicial na democracia. Revista Eletrônica Direito e Política, Programa de Pós-Graduação Stricto Sensu em Ciência Jurídica da UNIVALI, Itajaí, v.16, n.1, $1^{\circ}$ quadrimestre de 2021. Disponível em: www.univali.br/direitoepolitica - ISSN 19807791

De qualquer sorte, não podemos fugir do fato de que todo o poder, inclusive o poder absoluto, está sujeito a restrições factuais, razão pela qual a questão central neste debate não é só a de sabermos se os juízes estão justificando suas decisões e se estas realisticamente refletem razões deduzidas de maneira lógica e coerente do sistema jurídico como um todo; mas se os magistrados tem a seu dispor opções de escolha e decisão em face das múltiplas possibilidades de solução normativa dos casos que julgam mantendo a coerencialidade e integridade daquele sistema.

A afirmativa da resposta é inexorável, e as decisões colegiadas das Cortes bem demonstram isto, haja vista as distintas posições e votos de julgadores no mesmo órgão julgador, evidenciando posturas e interpretações distintas - e todas válidas - sobre os mesmos casos.

Por outro lado, poderíamos dizer que mesmo quando atribuímos a qualquer resposta judicial o adjetivo de boa/correta, tal fato não configuraria garantia alguma de termos também respostas ruins/incorretas sobre normas idênticas aplicadas aos mesmos casos.

E isto porque, ao fim e ao cabo, no plano da funcionalidade dos Tribunais, estaremos sempre expostos a possibilidades aplicativas/interpretativas de normas (e do sistema jurídico como um todo) maiores do que nossas escolhas e as decisões jurisdicionais, o que pode provocar, em algumas situações, alteração de leis decorrentes de decisões judiciais, o que seguramente não é o melhor para a Democracia. ${ }^{18}$

A despeito disto, não estamos defendendo que sejam insuperáveis e naturais os conflitos entre Jurisdição e Democracia nos dias atuais e em Sociedades e Mercados marcados por riscos e perigos os mais diversos, mas que estes protagonistas encontram-se, cada vez mais, em situações contingenciais de tensões e demandas de urgência/emergência a reclamar decisões e políticas

18 Ver o já clássico trabalho de BICKEL, Alexander. The Least Dangerous Branch. New Haven: Yale University Press, 1962. Ver também o texto de ALEXANDER, Larry. Constitutionalism, Philosophical Foundations. Cambridge: Cambridge University Press, 1998. 
GESTA LEAL, Rogério. Riscos e possibilidades do ativismo judicial na democracia. Revista Eletrônica Direito e Política, Programa de Pós-Graduação Stricto Sensu em Ciência Jurídica da UNIVALI, Itajaí, v.16, n.1, $1^{\circ}$ quadrimestre de 2021. Disponível em: www.univali.br/direitoepolitica - ISSN 19807791

imediatas, de todos e para todos, o que coloca certos cenários cambiantes de mobilidades mais ativas de uns, e mais inerciais de outros.

E não há nada de patológico nisto, pois se configuram como conjunturas próprias a serem gestadas por todos os sujeitos atingidos/alcançados pelas demandas e soluções consectárias. Como vão se resolver estas questões é o que devemos atentar em termos de asseguramento das conquistas civilizatórias da Democracia e seus espaços de debate, deliberação, decisão e execução de políticas e normas, evitando a concentração autoritária de iniciativas e resultados nestes campos, ao mesmo tempo em que garantindo sinergias positivas de equilíbrios (sempre tensos) dos processos de prevenção e solução destes temas.

Ou seja, não podemos buscar teses/perspectivas fundamentalistas e mágicas para responder aos desafios que tudo isto apresenta às relações políticas e sociais que se colocam à gestão de interesses e bens - públicos e privados - em nosso quotidiano, adotando de forma dogmática e radical propostas substancialistas e abstratas de petições de princípios desacopladas de suas necessárias mediações com o quotidiano do mundo da vida; como se a validade legal de determinados princípios e regras jurídicas legitimamente estatuídos possam, per si, garantir níveis pragmáticos de Democracia com aplicação imediata à realidade, descurando, pois, das interações fenomenológicas - e seus ruídos - que estes códigos normativos mantem com as relações humanas.

\section{CONSIDERAÇÕES FINAIS}

Duas noções aqui podem nos auxiliar a concluir estas reflexões: (1) a de que a Democracia Representativa como modelo tradicional de regime de governo, representa, mais do que o poder do povo, o poder exercitado em nome do povo; (2) a de que este Democracia, mais do que representar o poder do povo mediado pela representação, significa o conjunto de princípios regentes do Estado de Direito, condição de possibilidade para o exercício do poder pelo povo em qualquer situação, pela via da representação ou de forma direta. 
GESTA LEAL, Rogério. Riscos e possibilidades do ativismo judicial na democracia. Revista Eletrônica Direito e Política, Programa de Pós-Graduação Stricto Sensu em Ciência Jurídica da UNIVALI, Itajaí, v.16, n.1, $1^{\circ}$ quadrimestre de 2021. Disponível em: www.univali.br/direitoepolitica - ISSN 19807791

A primeira noção toma como referência a possibilidade de os juízes formarem instituição historicamente democrática, constituída a partir da deliberação popular representada, via Constituição, porque a Democracia não demanda da Sociedade como um todo que os cidadãos exerçam o poder por si próprios, ou que o façam por representantes eleitos.

Neste ponto, sendo o Judiciário eleito ou provido por concurso público, apresentase como instituição que está a serviço da Lei - não do povo; e nesta condição, por certo que tem limites de representação da vontade popular (que pode não ser lícita), mas também tem limites a atribuição de sentido da vontade da Lei (dados pelo próprio sistema jurídico).

Considerando até o fato de que o Poder Judiciário tem sua criação dada pela ordem constitucional - portanto, pelo Poder Constituinte originário -, que ele extrai a legitimidade de seus atos oficiosos diretamente da ordem constitucional, todavia, também está vinculado às decisões (igualmente originárias) tomadas pela soberania popular reunida em assembleia nacional constituinte, e em face de todas as demais normas consectárias/derivadas que formatam o sistema jurídico com um todo, não podendo vingar a tese de que o Poder Judiciário detém representação direta do povo! ${ }^{19}$

Neste ponto, em nosso sentir, o conceito de Democracia contemporânea está muito mais marcado pela ideia de sistema de governo, relações institucionais e sociais informadas por princípios morais, éticos e jurídicos, do que pela ideia demasiadamente generalizante de poder do povo.

Tal argumento leva em consideração que esta Democracia não pode ser limitada pela ideia de vontade da soberania popular, uma vez que esta equivale ao que

\footnotetext{
${ }^{19}$ Neste sentido, com o que não concordamos, a posição de ROSANVALLON, Pierre. La Démocratie Inachevée: histoire de la souveraineté du peuple en France. Paris: Gallimard, 2000, p. 407, no sentido de que os representantes do povo, enquanto eleitos, são os que detém o poder legitimo para constituir a vontade soberana; mas não são os unicos para o autor francês, pois defende ele que podem ser considerados também assim aqueles que falam, atuam e decidem em nome do povo, como a magistratura - constitucional e infraconstitucional. Na mesma direção ROUSSEAU, Dominique. Droit du contentieux constitutionnel. Paris: Montchrestien, 1999. Ver o texto de TREMBLAY, LuC B. General Legitimacy of Judicial Review and the Fundamental Basis of Constitutional Law. In Oxford Journal of Legal Studies. Vol. 23, nr. 4 (2003). Oxford: Oxford University Press, 2003, pp. 525-562.
} 
GESTA LEAL, Rogério. Riscos e possibilidades do ativismo judicial na democracia. Revista Eletrônica Direito e Política, Programa de Pós-Graduação Stricto Sensu em Ciência Jurídica da UNIVALI, Itajaí, v.16, n.1, $1^{\circ}$ quadrimestre de 2021. Disponível em: www.univali.br/direitoepolitica - ISSN 19807791

podemos chamar de ideia regulativa, ou tipo ideal, no sentido de que representam, modo geral, ideais a serem perseguidos como petição de princípio ordenador dos sistemas jurídicos, políticos, sociais, econômicos, dentre outros, condizentes à organização e funcionamento das relações humanas e institucionais, a serem dimensionadas objetiva e concretamente no cotidiano do mundo da vida.

Para além disto, e tratando da segunda noção referida, a vontade da soberania popular não pode, sempre, ser plenamente identificada - representada - pela vontade do Parlamento, ou mesmo pela vontade de maiorias, em face de evidenciarem eventuais fragmentos (majoritários) do todo - daí porque falarmos em fundamentos contramajoritários da Democracia.

Diante desta dificuldade de delimitarmos com segurança e de forma definitiva esta vontade (geral) popular soberana é que precisamos contar/considerar outros elementos mais diretivos à tais demarcações, como os referidos princípios e regras jurídicas que constituem o Estado Democrático de Direito, sendo os juízes apenas um dos garantidores destes, contando ainda com os demais protagonistas do Parlamento, do Poder Executivo e mesmo da Sociedade.

Se o sistema de justiça, pela via em especial dos juízes, não respeita aqueles limites e, por conta disto, vai instabilizando com variações semânticas e pragmáticas os comandos constitucionais e infraconstitucionais estabelecidos, cria muito mais fissuras do que integridade ao funcionamento da Democracia e das relações de poder que ela envolve.

\section{REFERÊNCIAS DAS FONTES CITADAS}

ALEXANDER, Larry. Constitutionalism, Philosophical Foundations. Cambridge: Cambridge University Press, 1998.

BICKEL, Alexander. The Least Dangerous Branch. New Haven: Yale University Press, 1962. 
GESTA LEAL, Rogério. Riscos e possibilidades do ativismo judicial na democracia. Revista Eletrônica Direito e Política, Programa de Pós-Graduação Stricto Sensu em Ciência Jurídica da UNIVALI, Itajaí, v.16, n.1, $1^{\circ}$ quadrimestre de 2021. Disponível em: www.univali.br/direitoepolitica - ISSN 19807791

BOBBIO, Norberto. Stato, Governo, Società. Per una teoria generale della politica. Turin: Giulio Einaudi, 1985.

BRUN, Henri; LEMIEUX, Denis. Politisation du pouvoir judiciaire et judiciarisation du pouvoir politique: la séparation traditionnelle des pouvoirs a-t-elle vécu? In Les Cahiers de droit, 18(2-3), 265-313, 1977. doi: $10.7202 / 042167 a r$

CRUET, Jean. A vida do direito e a inutilidade das leis. Lisboa: José Bastos \& Cia., 1990.

DWORKIN, Ronald. Taking Rights Seriously. Boston: Harvard University Press, 1977.

A Matter of Principle. Boston: Harvard University Press, 1985.

Law's Empire. Boston: Harvard University Press, 1986.

Life's Dominion. New York: Vintage Books, 1993.

Freedom's Law. Boston: Harvard University Press, 1996.

Sovereign Virtue: The Theory and Practice of Equality. Boston: Harvard University Press, 2000.

. Justice in Robes. Boston: Harvard University Press, 2006.

Is Democracy Possible Here? Principles for a New Political

Debate. Princeton: Princeton University Press, 2006.

Justice for Hedgehogs. Boston: Harvard University Press, 2011.

GÓMEZ, Enrique Serrano. Legitimación y Racionalidad. Weber y Habermas. Barcelona: Anthropos/Promat, 1994.

KASHYAP, Subhash. The citzen and judicial reforms under Indian polity. London: Hammick's Legal Bookshop, 2003. 
GESTA LEAL, Rogério. Riscos e possibilidades do ativismo judicial na democracia. Revista Eletrônica Direito e Política, Programa de Pós-Graduação Stricto Sensu em Ciência Jurídica da UNIVALI, Itajaí, v.16, n.1, $1^{\circ}$ quadrimestre de 2021. Disponível em: www.univali.br/direitoepolitica - ISSN 19807791

Political reforms for good governance - a policy brief.

Florida: W. Gaunt \& Co., 2007.

KELSEN, Hans. Teoría Pura del Derecho. Edición de 1934. Madrid: Trotta, 2011.

Teoría Pura del Derecho. Edición de 1960. Buenos Aires:

Eudeba, 2009.

KMIEC, Keenan D. Origin and Current Meanings of Judicial Activism. In California Law Review, Vol.92/1441 (2004). Disponível em: $<$ http://scholarship.law. berkeley.edu/californialawreview/vol92/iss5/4>. Acesso em: 19 nov. 2017.

LA LIGUE DES DROITS DE L'HOMME. Le pouvoir judiciaire et la separation des pouvoirs sous pression. Disponível em:< http://www.liguedh.be/wpcontent/uploads/2017/05/avril2017 analyse Idh pouvoir quilibre pouvoirs.pdf > . Acesso em 25 jun. 2018.

LEAL, Rogerio Gesta. A decisão Judicial: elementos teórico-constitutivos à efetivação pragmática dos Direitos Fundamentais. Chapecó: UNOESC, 2012. . Hermenêutica e Direito. Santa Cruz do Sul: EDUNISC, 2002.

MAHONEY, Paul. Judicial Activism and Judicial. Self-Restraint in the European Court of Human Rights: Two sides of the same coin. In Human Rights Law Journal, Vol. 11, nr. 1-2 (1990), p. 57-88.

MENGONI, Luigi. Ermeneutica e Dogmatica Giuridica. Milano: Giuffre, 2006.

OLDFATHER, Chad M. Defining judicial inactivism: models of adjudication and the duty to decide. Disponível em: <http://ssrn.com/abstract $=877002>$. Acesso em 20 out. 2017.

ROCHA, Leonel Severo. Epistemologia Jurídica e Democracia. Canoas: Editora Unisinos, 1998. 
GESTA LEAL, Rogério. Riscos e possibilidades do ativismo judicial na democracia. Revista Eletrônica Direito e Política, Programa de Pós-Graduação Stricto Sensu em Ciência Jurídica da UNIVALI, Itajaí, v.16, n.1, $1^{\circ}$ quadrimestre de 2021. Disponível em: www.univali.br/direitoepolitica - ISSN 19807791

ROSANVALLON, Pierre. La Démocratie Inachevée: histoire de la souveraineté du peuple en France. Paris: Gallimard, 2000.

ROUSSEAU, Dominique. Droit du contentieux constitutionnel. Paris: Montchrestien, 1999.

STRECK, Lênio Luis. Hermenêutica Jurídica em Crise. Porto Alegre: Livraria do Advogado, 2013.

SUNSTEIN, Cass R. A Constitution of many minds. Princeton: Princeton University Press, 2009.

TREMBLAY, LuC B. General Legitimacy of Judicial Review and the Fundamental Basis of Constitutional Law. In Oxford Journal of Legal Studies. Vol. 23, nr. 4 (2003). Oxford: Oxford University Press, 2003, p. 525-562.

TROPER, Michael. The Judicial Power and Democracy. Disponível em: $<$ http://diana-

n.iue.it:8080/bitstream/handle/1814/7714/EJLS $2007 \quad 12213$ TRO EN.pdf?seq uence $=1$ \&isAllowed $=y>$. Acesso em 25 jun. 2018.

VERMEULE, Adrian. Judging under uncertainty. Cambridge: Harvard University Press, 2006.

WARAT, Luis Alberto. A Pureza do Poder. Florianopolis: UFSC, 1983.

Senso Comum Teórico: as vozes incógnitas das

verdades jurídicas. In: Introdução Geral ao Direito. Porto Alegre: Fabris, 1994.

ZANNONI, Eduardo A. Crisis de la razón jurídica. Buenos Aires: Astrea, 2005.

RECEBIDO EM: ABR/2020

APROVADO EM: SET/2020 